\title{
Çocuklarda diz çevresi epifiz yaralanmalarında tedavi yaklaşımları
}

\section{Treatment approaches to epiphysis injuries around the knee in children}

\author{
Haluk Ağuş
}

SBÜ Tepecik Eğitim ve Araştırma Hastanesi, Ortopedi ve Travmatoloji Kliniği, İzmir

\begin{abstract}
Çocukların diz çevresi ağırlıklı olarak kıkırdak yapıdadır. Kıkırdak yapının direnci bağ ve tendonlardan zayıf olduğundan pediatrik diz yaralanmaları daha ziyade büyüme plağı yaralanmaları ve kopma kırığı olarak görülür. Femur alt uç ve tibia üst uç epifiz yaralanmaları, diz içi osteokondral kırıklar, patella kırıkları, tibianın dikeni ve tüberkülünün kırıkları en sık rastlananlarıdır. Yaralanma sonrası dizi şiş ve ağrılı olup hareketleri kısıtlı olan çocukta aksi kanıtlanmadıkça kıkırdak yapının yaralanabileceği akılda tutulmalıdır. Tanıda direkt grafiler esas olmakla birlikte özellikle kıkırdak yaralanmasından şüphelenilen olgularda MR yol gösterici olur. Epifiz ve eklem içi kırıkların çocuğun büyüme potansiyelini ve eklem işlevlerini olumsuz etkilemeyecek şekilde uygun yerleştirilmeleri ve sınırlı girişimsel yöntemlerle uygun tespitleri tedavinin esasını oluşturur. K-telleri ve vidalar sık kullanılan tespit araçlarıdır. Damar sinir yaralanmaları ve kompartman sendromu erken dönem komplikasyonlarıdır. Eklem sertliği, büyüme potansiyelinin olumsuz etkilenmesi nedeni ile uzunluk sorunları ve açısal şekil bozuklukları ile kopma kırıklarına bağlı olarak da eklem gevşekliği başlıca geç dönem komplikasyonlarıdır.
\end{abstract}

Anahtar sözcülkler: pediatrik diz; tibia dikeni (eminentia); tibia tüberkülü; osteokondral kırık
The structure of pediatric knee region is mostly cartilaginous. Since the resistance of cartilage to traumatic forces is weaker than the ligaments and tendons, pediatric knee injuries generally occur as growth plate injuries and rupture fractures. The most common are epiphyseal and avulsion fractures which are distal femur and proximal tibial epiphyseal injuries, osteochondral knee fractures, fractures of patella, tibial eminentia and tibial tubercule fractures. One should suspect an osteochondral fracture if the knee of a child becomes swollen with limited and painful weight bearing after the injury. Most of the injuries are diagnosed with plain radiographs but MR is gold standard for visualizing the occult injuries and osteochondral fractures. These fractures require accurate reduction and stable fixation with minimal invasive methods to minimize the growth disturbance and articular dysfunction. $\mathrm{K}$ wires and screws are commonly used implants for fixation. Neurovascular injuries and compartment syndrome are early complications while joint stiffness, growth disturbances and joint laxity can be diagnosed as a late complications.

Key words: pediatric knee; tibial eminentia; tibial tubercule; osteochondral fracture
Ç ocuklarda diz çevresi epifız yaralanmalarının önemi, gelişebilecek komplikasyonların ciddi sorunlara yol açabilme olasılıklarından ileri gelir. Diz çevresi vücudun en hızlı büyüyen bölgesidir ve büyüme plaklarının zarar görmesi büyüme potansiyelini olumsuz etkileyerek ciddi şekil bozukluklarına yol açabilir. ${ }^{[1]} \mathrm{Bu}$ yaralanmalar genellikle yüksek enerji gerektirdiğinden, komşu damar ve sinir yapılarının da tehlike altında olduğu, tanı ve tedavi sırasında göz önünde tutulmalıdır.

\section{FEMUR ALT UÇ EPIFIZ YARALANMALARI}

Bu yaralanmalar çocuk kırıklarının \%1'ini ve büyüme plağı yaralanmalarının \%1-6'sını oluşturur ve genellikle adolesan çağının yaralanmaları olarak görülür. ${ }^{[2]}$

Femurun alt uç epifizi vücudun en büyük ve en hızlı büyüyen epifizidir ve bu nedenle, yaklaşık olarak femur büyümesinin $2 / 3$ 'ünden, alt uzvun büyümesinin de $1 / 3$ 'ünden sorumludur. Dolayısıyla, yaralanma neticesi büyümenin zarar görmesi, ciddi şekil bozukluğu ve kısalık sorunlarına yol açabilir.

- Illetişim adresi: Prof. Dr. Haluk Ağuş, SBÜ Tepecik Eğitim ve Araştırma Hastanesi, Ortopedi ve Travmatoloji Kliniği, Yenişehir, İzmir Tel: 0232 - 4696969 / 1221 e-posta: halukagus@yahoo.com

- Geliş tarihi: 1 Eylül $2018 \quad$ Kabul tarihi: 1 Eylül 2018 
Femur alt uç büyüme plağı, düz bir hat olarak değil, dört ayrı kadran halinde kıvrımlar göstererek femur metafizine bağlıdır. Bu birleşme oldukça sağlam bir yapı oluşturduğundan, epifizin yaralanmaları yüksek enerjili kuwetler neticesinde oluşur. Anatomik yapıdaki bu özellik ve yüksek enerjili yaralanmalar nedeni ile, büyüme potansiyelinin olumsuz etkilenmesi bu yaralanmalarda daha sık izlenir.

Femur alt uç epifiz yaralanmaları genellikle taşıt çarpmaları veya spor yaralanmaları neticesinde oluşur. Büyüme plağının yaralanmalara olan direnci diz yan bağlarından düşük olduğundan, varus veya valgus yaralanmaları şeklinde büyüme plağı ayrılmaları bağ yaralanmalarına oranla daha sık izlenir. Yaralayıcı kuvvet önden gelip epifizin arkaya doğru yer değiştirmesine yol açmışsa, damar sinir yaralanmaları akılda tutulmalıdır.

Ender olarak, bu yaralanmalar doğum travması neticesinde ve hırpalanmış çocuk sendromunda da görülebilir. Olgunun dört yaşından küçük olması ve tedavi için geç getirilmesi, yaralanmayı açıklayacak bir mekanizmanın olmaması, küçük metafiz köşe kırıklarının saptanması, hırpalanmış çocuk olasılığını hatırlatmalıdır. ${ }^{[3]}$

Sınıflamada genellikle Salter-Harris sınıflaması kullanılır (Şekil 1). Tip I ve Tip II yaralanmalar daha sık görülür. Bu yaralanmalarda distal parçanın yer değiştirdiği yöndeki periost sağlamdır ve kırığın yerleştirilmesine yardımcı olabilir. Tip III ve Tip IV kırıklar eklem içi kırıklardır. Tip V kırıklar ender görülür ve geriye dönük olarak inceleme ile tanı konur. Femur kondillerinin koronal düzlemdeki kırıkları Hoffa kırığı olarak adlandırılır ve daha ziyade genç erişkinlerde izlenir. ${ }^{[4]}$

Klinik bulgular yaralanmanın şiddeti ve kırığın yer değiştirme miktarı ile orantılıdır. Ağrı, hassasiyet, basamama, yumuşak doku şişliği eklemde sıvı veya kan birikmesi, şekil bozukluğu ve bazen krepitasyon saptanabilir. Yer değiştirme genellikle varus veya valgus şeklindedir. Hiperekstansiyon yaralanmaları damar sinir yaralanmaları açısından özellikle değerlendirilmelidir.

Olguların çoğunda iki yönlü düz röntgen filmleri tanı için yeterli olur. Oblik grafiler az yer değiştirmiş Tip III kırıkların değerlendirilmesinde yararlı olabilir. Şiş, ağrılı ve dengesizlik saptanmış dizlerde zorlamalı grafiler tanıda yardımcı olabilirse de, uygulama sırasında gerekli analjezi sağlanıp hastanın kas spazmı aşılmaIıdır. Zorlamalı grafi incelemesi yapılacaksa, aşııı zorlama yapıp yaralanma derecesini arttırmamaya dikkat edilmelidir. Özellikle eklem içi olan yaralanmalarda ve şüphede kalınan olgularda manyetik rezonans (MR) incelemesi gerekir. Bu sayede kırığın ve varsa eşlik eden

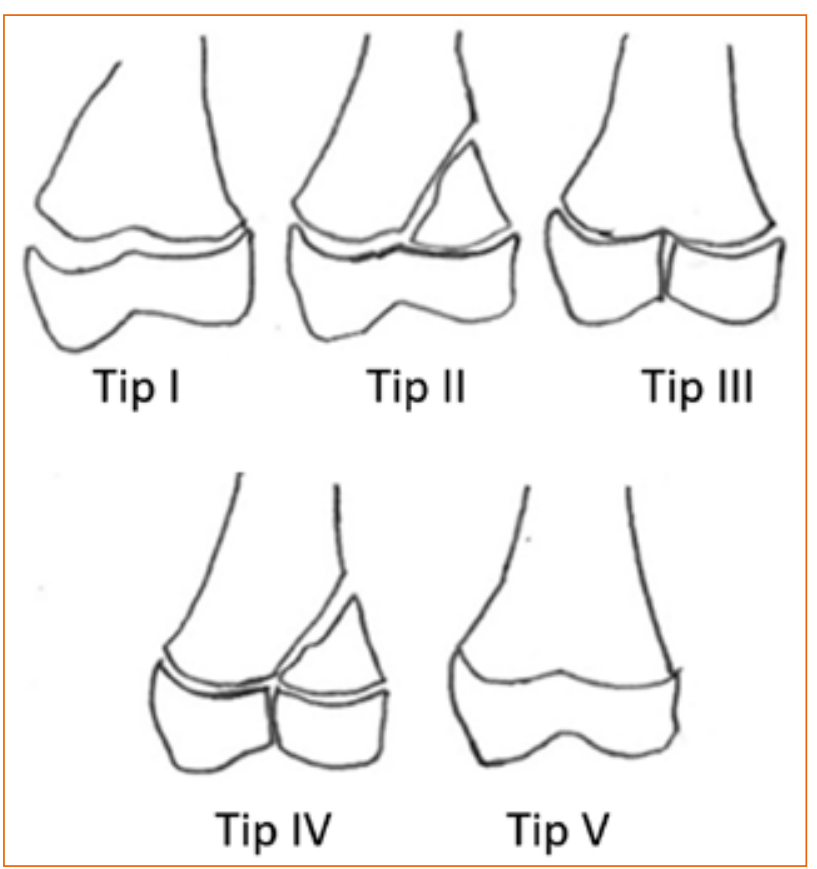

Şekil 1. Epifiz yaralanmalarında sıklıkla kullanılan Salter Harris sınıflamasının femur alt uç epifiz yaralanmalarındaki şematik görünümü.

bağ yaralanmalarının ve osteokondral kırıkların daha iyi değerlendirilmesi mümkün olur. ${ }^{[5]}$

Özellikle hiperekstansiyon yaralanmalarında ayrıntılı damar sinir bakısı yapılmalıdır. Akut iskemi bulguları -nabız yokluğu, soğukluk, solukluk, siyanoz, gecikmiş kapiller dolma- saptanırsa kırığın acil yerleştirilmesi gerekir. Yerleştirilmeden sonra akut iskemi bulguları düzelmezse, damar yaralanması düşünülüp gerekli girişimler yapılmalıdır. Akut iskemi bulgularının düzeldiği olgular ise gelişebilecek iskemi bulguları ve kompartman sendromu yönünden yakın gözlem altında tutulmalıdır. Bu sürede yaralanmış uzuv atellenip tespite alınmalı, yükseltilmeli ve soğutulmalıdır.

Yer değiştirmemiş Tip I ve Tip II kırıklar konservatif olarak tedavi edilebilir. Diz üstü alçı tespiti genellikle yeterli olursa da uyumsuz hastalarda pelvi pedal alçı tespiti uygulanmalıdır. ${ }^{[6]}$ Konservatif olarak tedavi edilen kırıklarda yerleştirmenin bozulmasının erken tanısı için haftalık radyolojik izlem gereklidir.

Yer değiştirmiş Tip I ve Tip II kırıklarla tüm Tip III ve Tip IV kırıklar anestezi altında kapalı yerleştirme ve perkütan çivileme ile tespit edilebilir. Yerleştirme anestezi altında yapılmalıdır. Tip I ve Tip II kırıklar için distal parçanın kaydığı yöndeki periost sağlam olduğundan traksiyon uygulanıp distal parça aksi yöne doğru 

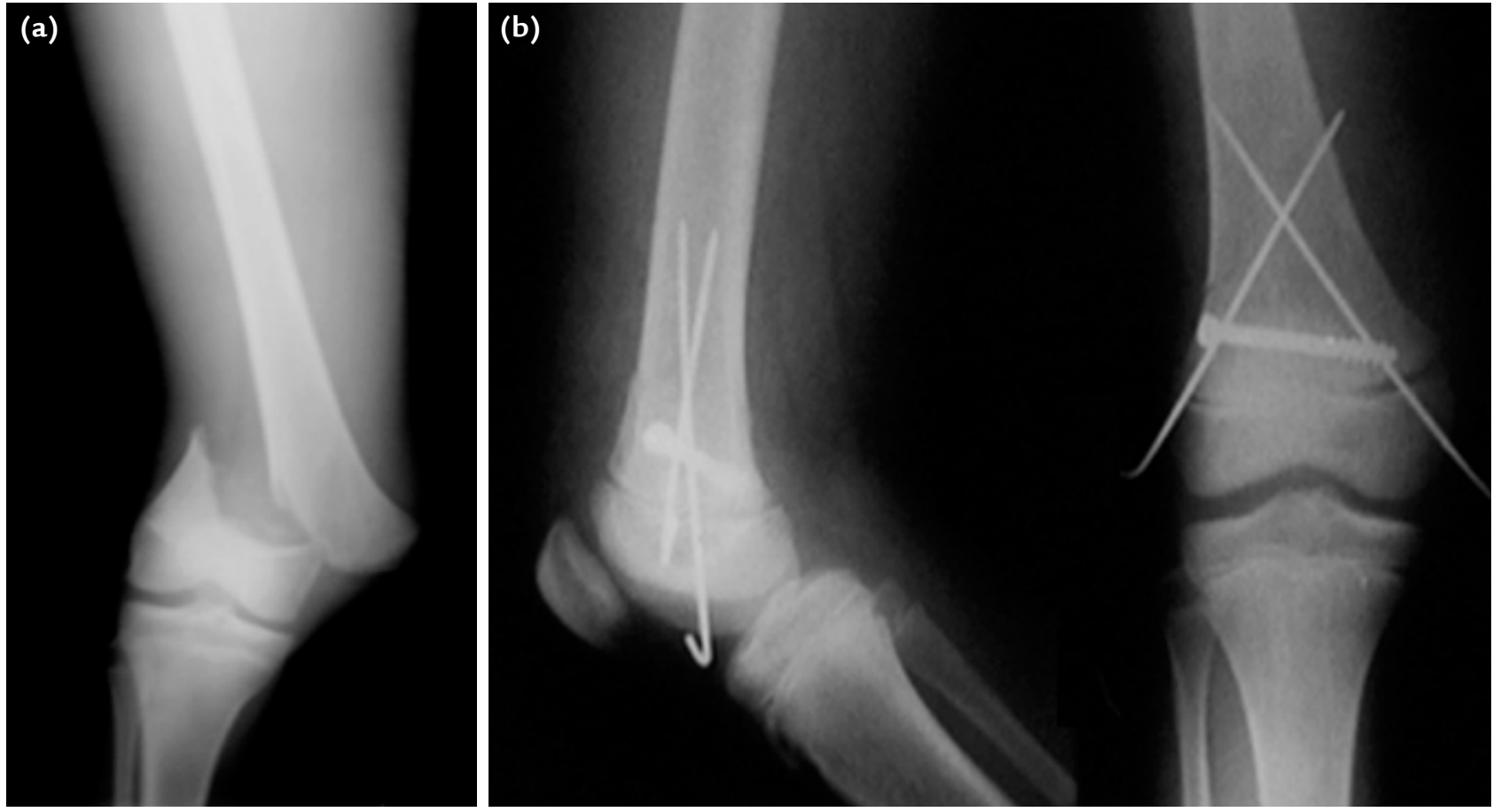

Şekil 2. a, b. Tip II femur alt uç epifiz yaralanması (a). Kırığın yerleştirilip perkütan vida ve K-teli ve vida ile tespiti (b).

kaydırılarak uygun yerleştirme sağlanabilir. Tip III ve Tip IV kırıkların yerleştirilmesinde perkütan olarak kullanılacak yerleştirme pensi veya distal parçadan geçirilecek bir K-teli yerleştirme gereci olarak kullanılabilir.

Uygun yerleştirme sağlandıktan sonra Tip I ve Tip II kırıklar çarpraz K-telleri ile perkütan olarak tespit edilir (Şekil 2). Tip III ve Tip IV kırıkları ise büyüme plağını geçmeyen distal parçanın bulunduğu taraftan uygulanacak transvers K-telleri veya perkütan olarak uygulanabilecek kanallı spongiyöz vidalarla tespit etmek mümkündür. Yerleștirme ve tespit aşamaları skopi ile kontrol edilmelidir. Gerekli tespit ve denge sağlandıktan sonra diz $20-30^{\circ}$ fleksiyonda diz üstü alçı tespiti uygulanır. K-telleri dört hafta sonunda çekilir ve altı hafta sonunda alçı çıkarılarak rehabilitasyona başlanır.

Açık yerleştirme ve içten tespit kapalı olarak yerleştirilemeyen Tip I ve Tip II kırıklarla, eklem içi kırık olduklarından anatomik olarak yerleştirilmesi gereken Tip III ve Tip IV kırıklara uygulanır (Şekil 3). Tip I ve Tip II kırıklara yer değiştirme yönünün aksi yönünden yapılacak kesi ile yaklaşılır. Böylece zarar görmemiş periost korunur ve yerleştirmeyi engelleyen bir yumuşak doku sıkışmasını görmek mümkün olabilir. Tespit çarpraz K-telleri ile sağlanır.
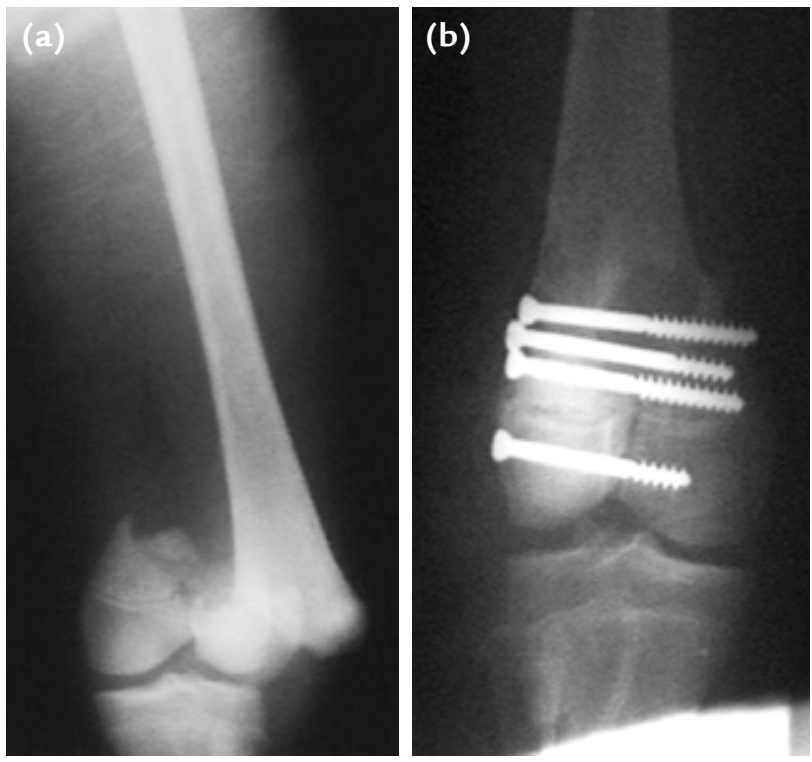

Şekil 3. a, b. Tip IV femur alt uç epifiz yaralanması (a). Kırığın açık yerleştirme ve büyüme plağını geçmeyen vidalarla tespiti (b).

Tip III kırıklar için ise distal parçanın bulunduğu yere göre anteromediyal veya anterolateral kesi yapılır. Anatomik yerleştirme sağlandıktan sonra tespit büyüme plağını geçmeyen yatay olarak epifizden geçen kansellöz vidalarla sağlanır. 
Tip IV kırıklar için ise metafiz parçasının olduğu taraftan kesi yapılmalıdır. Uygun yerleştirme sağlandıktan sonra metafiz parçasından konulacak ve büyüme plağını geçmeyen iki adet kansellöz vida ile tespit sağlanır. Tespit yeterince dengeli değilse epifizden yatay olarak konulacak kansellöz vida ile denge arttırılır (Şekil 3).

Açık yerleştirme ve tespit sonrasında altı hafta süre ile uzun bacak alçısı uygulanır. Bu süre sonunda alçı çıkarılıp diz hareketlerine başlanır. Yük vermek için kırığın tam olarak iyileşmesi beklenmelidir.

Femur alt uç epifiz yaralanmalarının erken dönem komplikasyonları; damar sinir yaralanması, bağ ve menisküs yaralanmaları ve kırığın yer değiştirmesidir.

Femur alt uç epifiz kırıklarında damar yaralanması ve kompartman sendromu \%1 oranında görülür. ${ }^{[7]}$ Peroneal sinir yaralanması ise \%7 oranında saptanır. Damar yaralanmaları acil girişim gerektirmekle birlikte, peroneal sinir yaralanmaları üç ay içinde iyileşir ve acil girişim gerektirmez.

Bu yaralanmalarla birlikte görülebilecek menisküs ve bağ yaralanmalarının kırık tedavisi sırasında değil, ancak kırık iyileştikten sonra değerlendirilmesi önerilmektedir. ${ }^{[8]}$

Yer değiştirmesi veya tanısının konulması travmadan 7-10 gün sonra olan Tip I ve Tip II kırıkların, büyüme kıkırdağının daha fazla zarar görmemesi için yerleştirilmeye çalışıımaması ve yanlış kaynamanın kabul edilerek yeniden şekillenmenin beklenmesi gerekir. ${ }^{[9]}$ Gelişebilecek şekil bozukluğunu, çocuğun yaşı da göz önünde tutularak, epifizyodez veya osteotomi ile düzeltmek mümkün olabilir. Geç dönemde görülen en önemli komplikasyon büyüme bozukluğunun gelişmesidir. Bu soruna bağı olarak şekil bozuklukları ve alt uzvun uzunluk eşitsizliği gelişebilir. Çocuğun yaşının küçük olması ve kırık parçanın yer değiştirme oranı bu komplikasyonun gelişmesine doğrudan etkilidir.

Şekil bozukluğu ve uzunluk farkının gelişip gelişmediği altı aylık aralarla yapılan klinik kontrollerle izlenmelidir. Bu izlemlerde radyolojik olarak saptanacak Harris çizgileri önemlidir. Harris çizgisi iki düzlemde de görülebilen metafizer çizgilerdir ve yaralanmadan sonra büyümenin durakladığının belirtisidir. Yaralanma sonrası Harris çizgilerinin metafize paralel olarak saptanması, büyümenin normal olarak devam ettiğinin göstergesidir.

İlerleyici şekil bozukluğu, yanlış kaynama veya bölgesel olarak gelişmiş kemik köprünün büyümeyi olumsuz olarak etkilemesinden kaynaklanabilir. Yanlış kaynama neticesi oluşmuş şekil bozukluğunu osteotomi veya hemiepifizyodez ile düzeltmek mümkün olabilir.
Illerleyici şekil bozukluğunun düzeltilmesi ise büyüme bozukluğuna yol açan kemik köprünün çıkarılması, osteotomi ve sağlam büyüme plağına uygulanacak epifizyodezle sağlanabilir. Kemik köprünün çıkarılması, köprünün genişliğinin büyüme plağı alanının \%50'sinden az olmasına ve iki yıldan fazla büyüme potansiyelinin olmasına bağlıdır. ${ }^{[10]}$ Çevresel kemik köprünün çıkarılmasının sonuçları, merkezi olanlara oranla daha etkili olmaktadır. Kemik köprü, sağlam büyüme kıkırdağına gelene kadar yüksek hızlı oyucularla törpülenerek çıkarılır ve oluşan boşluk kemik köprünün tekrar oluşmasını engellemek için çeşitli biyolojik maddelerle (otolog yağ dokusu, kemik çimentosu) doldurulur. ${ }^{[11]}$ Büyümeyi izlemek için epifiz ve metafize metal işaretler konur. Varus ve valgus şekil bozukluğu $20^{\circ}$ 'den fazla ise, kemik köprünün çıkarılması ile birlikte düzeltici osteotomi de yapılmalıdır.

\section{TiBiA DIKENI (EMINENSIYA) KIRIKLARI}

Ön çarpraz bağın yapışma yeri olan tibia dikeni kırıkları, genellikle bağın aşırı gerilmesine neden olan dizin hiperekstansiyonu neticesi oluşur. Erişkinlerde ön çarpraz bağın kopmasına neden olacak güçler, dikenin tam kemikleşmemesi sonucu kırık olarak görülür. Özellikle 5-15 yaşlar arasında ve genellikle bisikletten düşme neticesinde oluşur.

Kırık sınıflamasında Meyers ve McKeever sınıflaması kullanılır. ${ }^{[12]}$ Tip I kırıklarda ön kenarda hafif ayrışma, Tip II kırıklarda arka tarafa menteşe gibi bağlı olacak şekilde ön tarafın ayrılması ve Tip III kırıklarda tamamen ayrışma mevcuttur (Şekil 4). Kırık parçanın parçalı olması durumu ise Tip IV kırık olarak sınıflanmıştır.

Fizik muayenede ağrı, hassasiyet ve dizde hemartrozun neden olduğu şişlik vardır. Diz hareketleri kısıtlıdır. Direkt radyografi ve özellikle yan diz grafisi tanı koydurucudur. Şüpheli durumlarda bilgisayarlı tomografi (BT) ve MR yaralanmanın daha ayrıntılı değerlendirilmesine yardımcı olur.

Tip I kırıklar konservatif olarak tedavi edilir. Diz 10-20 fleksiyonda 4-6 haftalık diz üstü silindirik alçı tespitine alınır. Yerleştirilemeyen Tip II ve tüm Tip III ve Tip IV kırıklar cerrahi olarak tedavi edilir. Cerrahi girişim, cerrahın deneyimine bağlı olarak doğrudan veya artroskopik yardımla beraber sınırlı kesilerden yapılır (Şekil 5). Kırık parçalar çevresel olarak emilebilen, epifiz periferinden çıkan veya büyüme plağını geçen dikişler, ince teller veya mini vidalarla tespit edilir. ${ }^{[13]}$ Kırık parça yatağa iyice oturtulmalı ve erken rehabilitasyona izin verecek şekilde tespit edilmelidir. Tedavi sonunda ekstansiyon kaybı ve bir miktar bağ dengesizliği görülebilirse de, bu durum klinik sonucu çok etkilemez. ${ }^{[14]}$ 


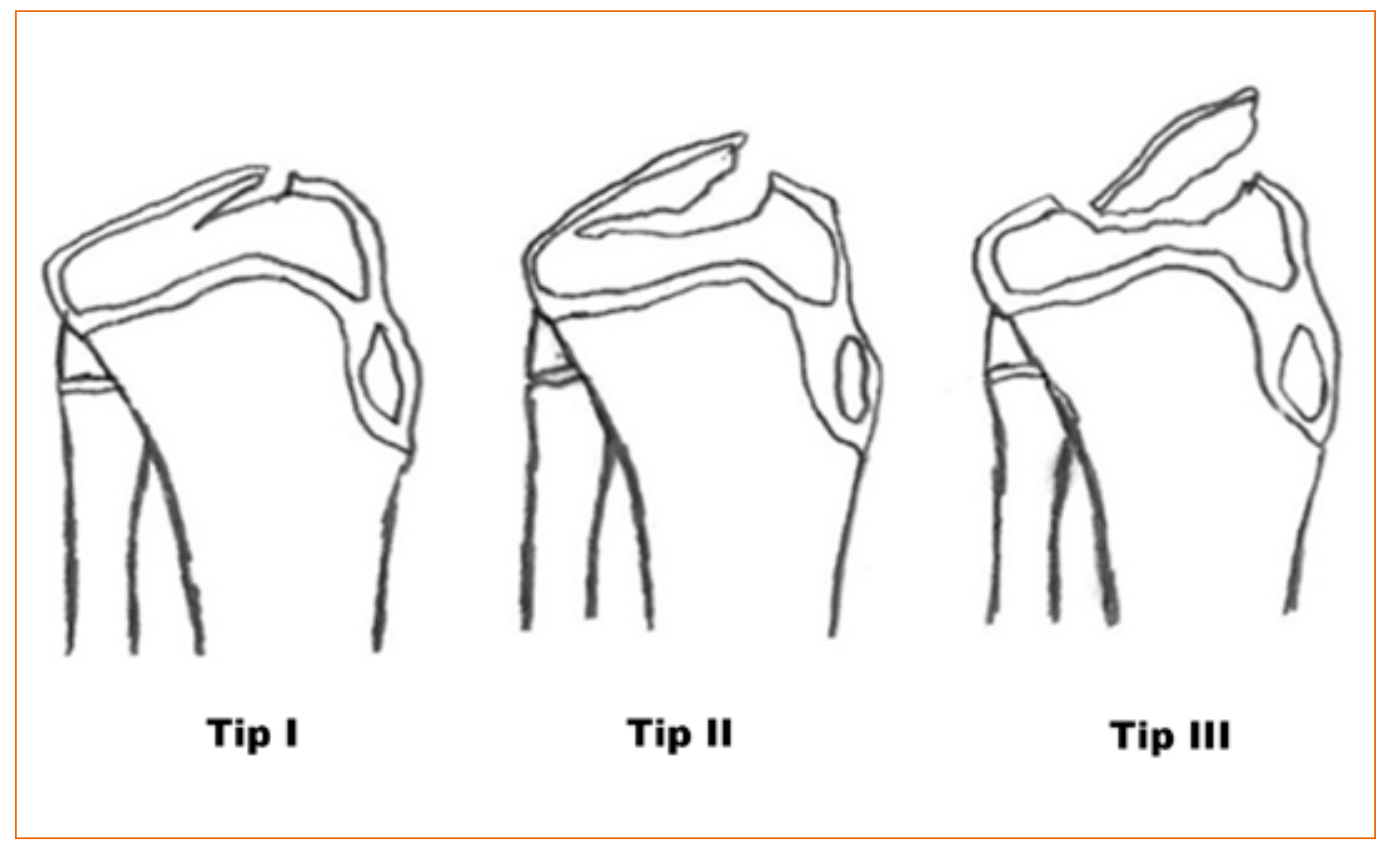

Şekil 4. Tibia dikeni kırıklarının Meyers McKeever sınıflandırması: Tip I, ayrışma göstermeyen kırık; Tip II, kırık parçanın ön kısmı ayrışıı̧ ancak arka kııım ayrışmamış; Tip III, kırık parça tam olarak ayrışmış.
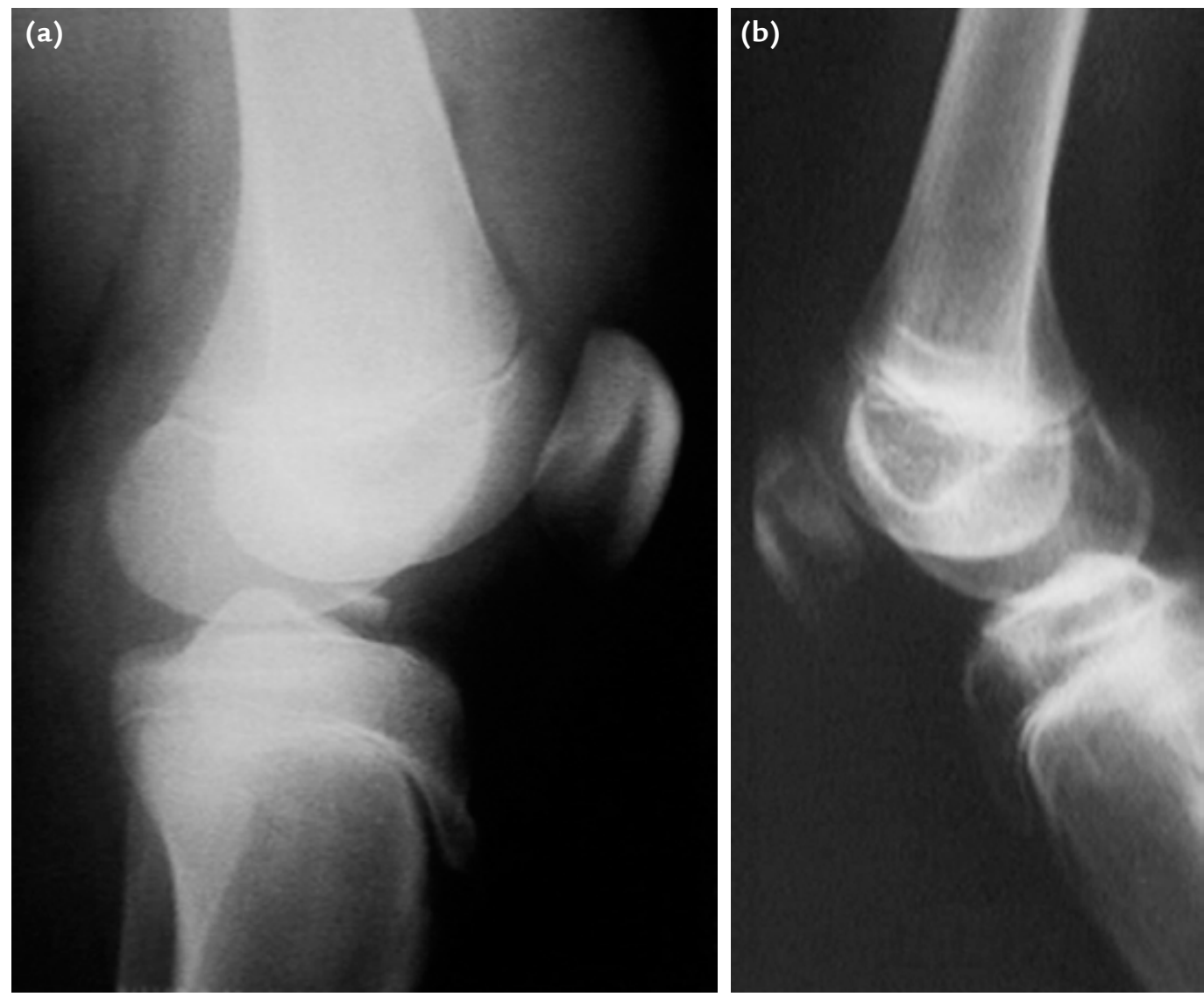

Şekil 5. a, b. Tip III tibia dikeni kırığı (a). Artroskobik olarak yerleştirilip çevresel dikişle tespit. Ameliyat sonrası 1. yıl (b). 

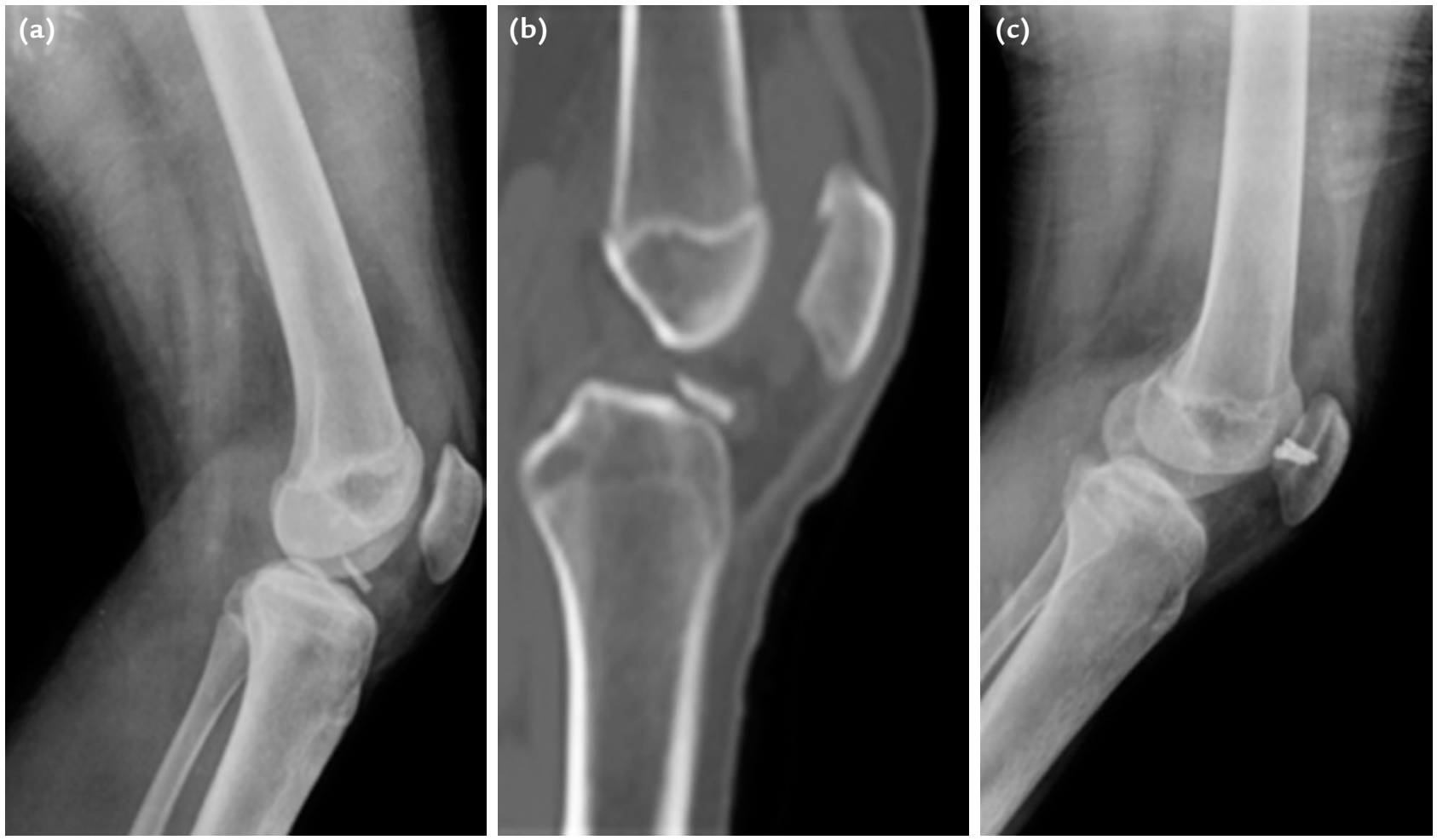

Şekil 6. a-c. Osteokondral kırık (a). Osteokondral kırığın patelladan ayrıldığı görülüyor (b). Osteokondral kırığın Herbert vidası ile tespiti (c).

\section{OSTEOKONDRAL KIRIKLAR}

Genç erişkinlik döneminde izlenir. Fleksiyon halindeki dize gelen doğrudan travma veya travmatik patella çıkığı sonucu oluşan makaslama güçleri neticesinde oluşur. ${ }^{[15]}$

Akut travmatik patella çıkığı olgularında, aksi ispatlanana kadar, osteokondral kırık olasılığı akılda tutulmalıdır. Şiş ve hareketleri kısıtlı olan dizde ponksiyon sıvısında yağ granüllerinin görülmesi osteokondral kırığı düşündürmelidir. Kıkırdak parçanın büyüklüğüne bağlı olarak direkt radyolojik inceleme ile tanı zor olabilir. Tanıda MR altın standarttır. ${ }^{[16]}$

Tedavi genellikle cerrahidir.[17] Yük taşımayan yüzeylerin küçük parçaları artroskopik olarak çıkarılabilir. Yük taşıyan yüzeylerin kırıkları ise tespit edilmelidir. Tespit için mini-AO veya Herbert vidaları, K-telleri, eriyen vidalar veya fibrin yapıştırıcılar kullanır (Şekil 6). ${ }^{[18-20]}$ Kırık travmatik patella çıkığı sonucu oluşmuşsa, çıkığın tekrarlamasını önlemek için kırık tespit edilirken iç yan retinakulum ve patella femoral bağ da onarılmalıdır. Tespit sonrasında diz cihazlanır ve kırık iyileşene kadar yük verme engellenir.

\section{PATELLA KIRIKLARI}

Patella çocuklarda kıkırdak yapıda ve çok hareketli olduğundan, erişkinlerde sık görülen parçalı ve transvers patella kırıkları çocuklarda ender izlenir. Çocuklara has patella kırı̆̆ı eldiven tipi kopma kırığıdır. Bu kırıklar genellikle patellanın alt kutbunda ve kuadriseps kasının ani kasılmasına neden olan kuvvetli zıplama veya tekrarlayııı gerilim kuvvetleri neticesinde oluşur. ${ }^{[21,22]}$ Daha ziyade 8-12 yaşlarında görülür.

Çocuğun dizi şiştir ve hareketleri ağrılıdır. Dizin aktif ekstansiyonu özellikle dirence karşı zordur. Palpasyonla patellanın üst veya alt kutbunda doku devamsızlığı bulunabilir.

Direkt grafiler genellikle tanı koydurucudur. Diz $30^{\circ}$ fleksiyonda iken çekilen yan grafi ile patellanın yer değiştirme miktarı daha kolay saptanır. Klinik bulgular ve direkt grafi ile tanı konulamıyorsa MR ve ultrasonografi (US) tanıyı kesinleştirir. Yer değiştirmemiş kırıklarda dizi altı hafta süre ile tam ekstansiyona almak yeterlidir. Üç milimetreden fazla yer değiştirmiş transvers patella kırıkları erişkinlerinki gibi tedavi edilir. Eldiven kırıkları ise anatomik olarak yerleştirildikten sonra periferik dikişlerle veya yeterli kemik doku varsa gergi bandı tekniği ile tespit edilir. ${ }^{[22]}$ 


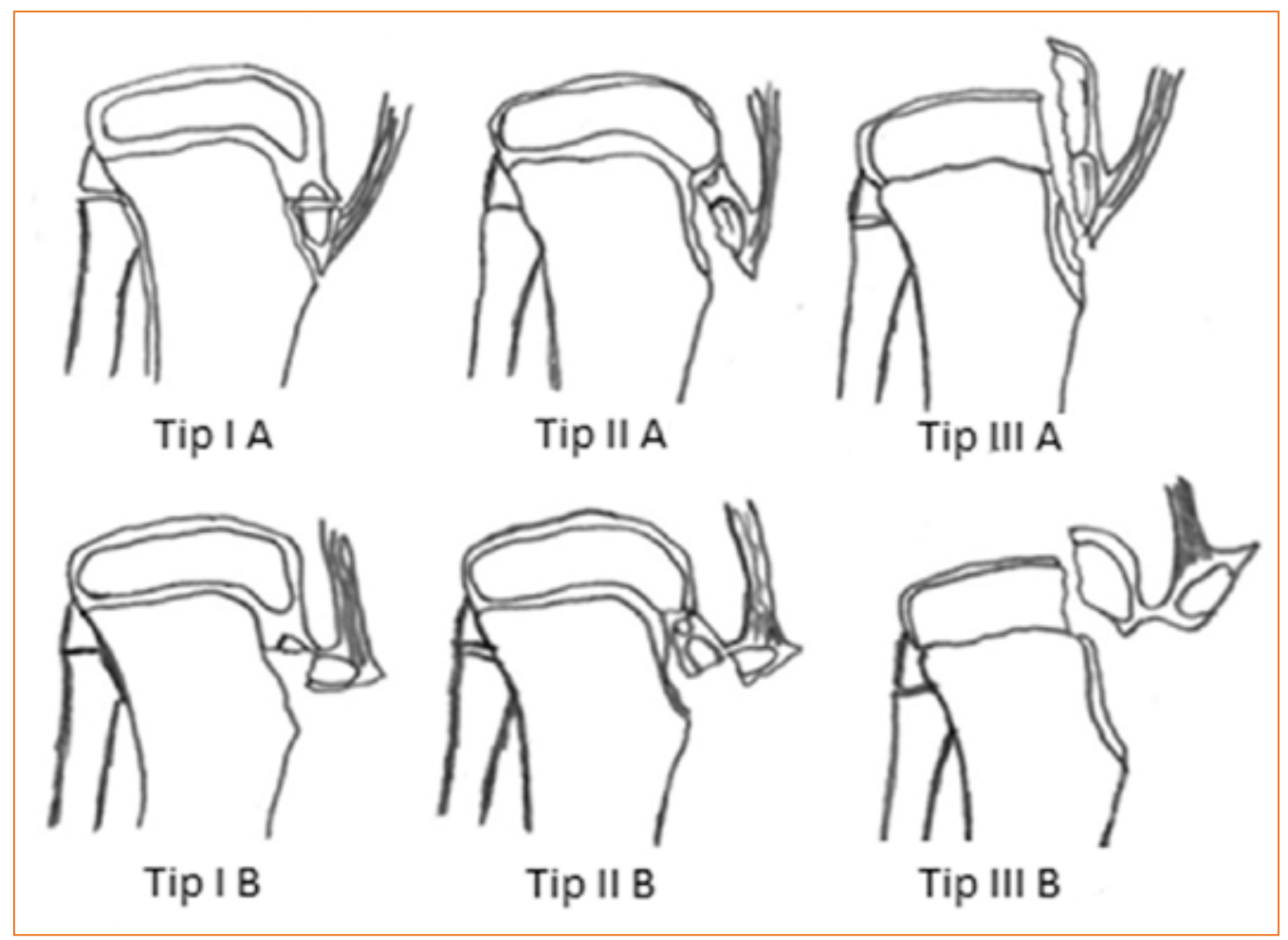

Şekil 7. Tibia tüberkülünün kopma kırıklarının sınıflaması.

\section{TiBi|A TÜBERKÜLÜ KIRIKLARI}

Tibianın tüberkül kırıkları ender kırıklardır ve çocuk kırıklarının \%0,4-2,7'sini oluşturur. ${ }^{[2]}$ Tibia tüberkülü, tibia üst uç büyüme plağının öne ve distale uzanımıdır. Tibia tüberkülünün büyüme plağı 7-9 yaşlarına kadar fibröz kıkırdak yapısında olduğundan çekme güçlerine daha dayanıklıdır, ancak bu yaştan sonra normal büyüme kıkırdağının kolonlu yapısına dönüştüğünden bu direnci düşer. $O$ nedenle, tüberkül kırıkları genellikle 12-17 yaşlarında ani atlama ve zıplamayı gerektiren spor aktiviteleri neticesi oluşur. ${ }^{[23]}$

Fizik bakıda şişlik, kırık bölgesinin duyarlılığı ve dizin ekstansiyonunda sınırılık vardır. Kırık eklem içine uzanıyorsa hemartroz olabilir. Lateral radyografi tanı koydurucudur. Tibia tüberkülü orta hattın lateralinde yer aldığından, lateral grafi hafif internal rotasyonda çekilirse kırık daha kolay saptanır. Yaralanmanın eklem içi tutuluş ve eşlik eden yumuşak doku yaralanmaları BT ve MR ile değerlendirilmelidir.

Radyolojik veriler Ogden sınıflamasına göre değerlendirilir (Şekil 7). ${ }^{[24]}$ Tip I'de tüberkül distalinden ayrılmıştır ve kırık hattı kemikleşme merkezinden geçer.
Tip I A'da minimal ayrılma, Tip I B'de distal parçanın metafizer ayrılması vardır. Tip Il'de kemikleşme merkezi metafizden ayrılmıştır. Tip II A'da kemikleşme merkezinde parçalanma yoktur, Tip II B'de kemikleşme merkezi parçalanmıştır. Tip III'te eklem içi uzanım vardır. Ayrılan parça Tip III A'da parçalanmamış, Tip III B'de ise parçalıdır.

Çok az kaymış kırıklarda, diz ekstansiyonda iken uygulanan 4-6 haftalık uzun bacak alçısı yeterlidir. Tip II ve Tip III kırıklar cerrahi olarak tedavi edilir. Ayrılan parça anatomik olarak yerleştirilmelidir. Tespit kansellöz vidalar, K-telleri, gergi bandı ve periost dikişleri ile yapılabilir. Tespitten sonra dizi tam ekstansiyonda tutacak 4-6 haftalık silindirik alçı uygulanır (Şekil 8).

Bu yaralanmanın erken komplikasyonu olarak anterior tibia arterinin yaralanıp tibianın ön kompartmanına olan kanama neticesi kompartman sendromu gelişebilir. Özellikle Tip II ve parçalı kırıklarda görülür. Geç komplikasyon olarak büyüme plağının erken kapanması neticesinde genu rekurvatum gelişebilir. Hafif şekil bozukluklarında proksimal tibia epifizyodezi, ağır şekil bozukluklarında ise tibia fleksiyon osteotomisi gerekebilir. 

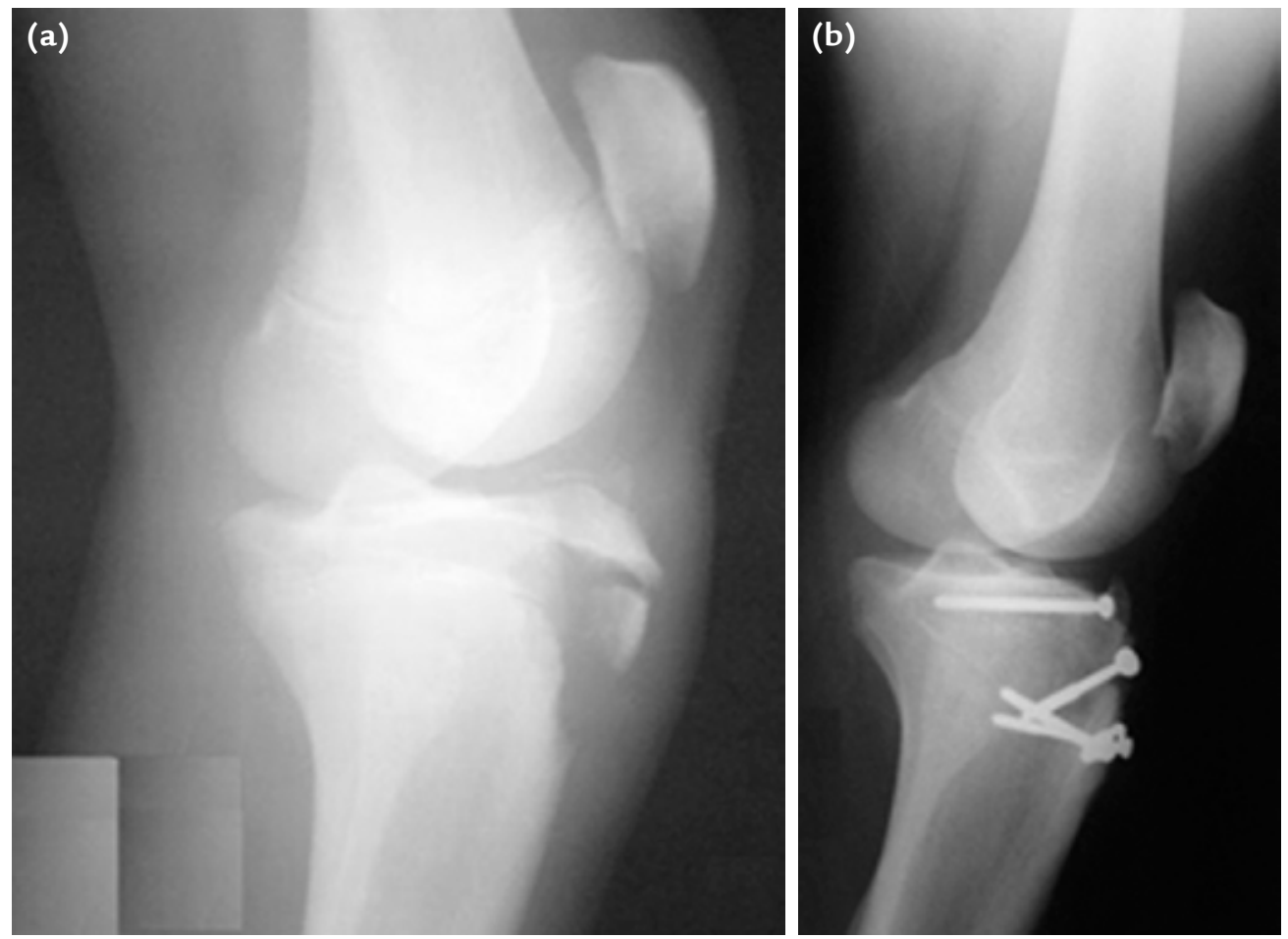

Şekil 8. a, b. Tibia tüberkülünün Tip III B kırığı (a). Kırığın metafiz ve epifizden geçen vidalarla tespiti (b). (Ali Biçimoğlu'nun izni ile)

\section{TIBBiA ÜST UÇ BÜYÜME PLAĞı YARALANMALARI}

Tiba üst uç epifiz yaralanmaları çocuklarda epifiz yaralanmalarının \%2'ini oluşturur. ${ }^{[2]}$ Diz yaralanmaları çocuklarda sık olmasına rağmen büyüme plağı yaralanmalarının ender olması, tibia üst uç epifizinin bazı anatomik yapılarca korunur olması ile açıklanır. ${ }^{[25]}$ Tibia tüberkülünün metafiz parçası ön tarafta, fibula başı lateralde ve semitendinöz tendonu posteromediyaldeki başlıca koruyucu anatomik yapılardır.

Tibia üst uç büyüme plağı, kadınlarda daha erken olmak üzere, 15-17 yaşlarında arkadan öne doğru kapanır. Bu büyüme plağının aktivitesi ile tibia uzunluğunun $1 / 2$ 'si ve alt uzuv uzunluğunun $1 / 4$ 'ü oluşur. ${ }^{[26]} \mathrm{O}$ nedenle, büyüme aktivitesini olumsuz olarak etkileyecek yaralanmalar ciddi kısalık ve şekil bozukluklarına yol açabilir. Oluşacak sorunun ciddiyeti yaralanma yaşı küçüldükçe artar.

Popliteal arter, tibia üst uç epifizinin proksimaline çok yakın komşulukla soleus bandını geçip peroneal arter, posterior tibial arter ve anterior tibial arter olmak üzere üç dala ayrılır (Şekil 9). Bu komşuluk nedeni ile özellikle tibia üst uç metafizinin arkaya doğru yer değiştirdiği hiperekstansiyon yaralanmalarında

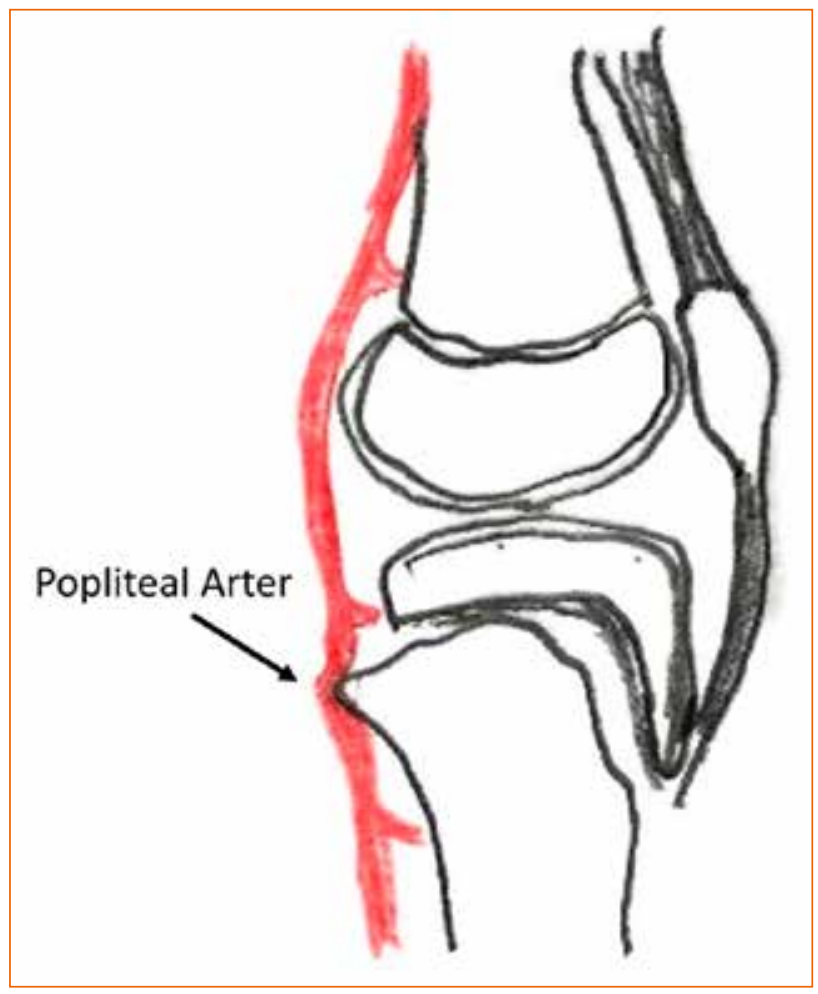

Şekil 9. Tibianın üst uç epifiz yaralanmalarında hemen arkada yer alan popliteal arter risk altındadır. 
popliteal arterin gerilme veya yırtılmasına bağı olarak damar yaralanması görülme olasılığı artar. ${ }^{[27]}$

Tibia üst uç epifiz yaralanmaları genellikle sabit diz çevresine uygulanan abduksiyon veya hiperekstansiyon kuwvetleri ile oluşur. Bu tür yaralanmalar genellikle spor aktiviteleri ve özellikle araç çarpması neticesinde meydana gelir.

Sınıflamada Salter Harris sınıflaması kullanılırsa da, kırık parçalarının yer değiştirme yönüne göre yapılacak sınıflama tedavi ve sorunların tanımlanmasına yardımcı olabilir (Şekil 10). Damar yaralanmaları genellikle hiperekstansiyon yaralanmalarında izlenir. En sık izlenen valgus yaralanmalarına ise fibula başı kırığı ve lateral metafiz kırı̆ğı eşlik edebilir. Fleksiyon tipi kırıklarda da epifizin ayrılması önden tuberositas tibianın ayrılması şeklinde başlayıp büyüme plağı boyunca arkaya doğru devam eder ve sık olarak genç erişkinlerde görülür. Bu bölgenin, tibianın üst uç epifizinin asimetrik kemikleşmesine bağlı olarak, ayak bileğinde olduğu gibi üç düzlemli kırıkları da tanımlanmıştır. ${ }^{[28]}$

Lateral tibia kondilinin iki tip kopma kırığı da tanımlanmıştır. ${ }^{[29]}$ Segond kırığı olarak tanımlanan tipte parça intra-epifizyeldir ve eklem yüzü ile büyüme plağı arasından kopmuştur. Genellikle lateral eklem kapsülü ve ön çarpraz bağ yaralanması ile birliktedir. Kopma kırığının diğer tipi ise eklem yüzü ve büyüme plağını içerecek şekilde Gerdy tüberkülünün kırı̆̆ıdır.

Klinik olarak dizde ağrı, şişlik, hareket kısıtlılığı ve yüklenememe vardır. Tibia üst uç yaralanmalarında ayrıntılı damar sinir bakısı yapılmalı ve kayıt altına alınmalıdır. Distal nabızlarla posterior tibial ve peroneal sinirlerin fonksiyonları kontrol edilmelidir. Akut iskemi bulgularının varlığında kırığın acil yerleştirilmesi yapılmalı, bulgular yerleştirmeden sonra da devam ediyorsa damar yaralanmasına hemen müdahale edilmelidir. Yerleştirmeden sonra, var olmayan nabızların geri dönmesi ve iskemi bulgularının kaybolması ardından olgunun birkaç gün yakın izlenmesi gerekir.

íki yönlü tibia üst uç grafileri tanı için genellikle yeterli olur. Klinik bulguları bulunan ancak grafileri normal görülen olgularda anestezi altında çekilecek zorlamalı grafilerle kesin tanı konabilirse de, zorlama anında mevcut yaralanma derecesini arttırmamaya dikkat edilmeli ve hiperekstansiyon zorlaması yapılmamalıdır. BT kırığın daha iyi tanınmasına, MR ise büyüme plağı ve yumuşak dokuların ayrıntılı değerlendirilmesine yardımcı olabilir.

Yer değiştirmemiş tüm kırık tipleri ve yerleştirmeden sonra dengeli olan Salter Harris Tip I ve Tip II kırıklar konservatif olarak diz üstü alçılama ile tedavi edilebilir. Kırık yerleştirilmesi, oluş mekanizmasının aksi yönünde uygulanacak menevra ile sağlanır ve o konumda tespit

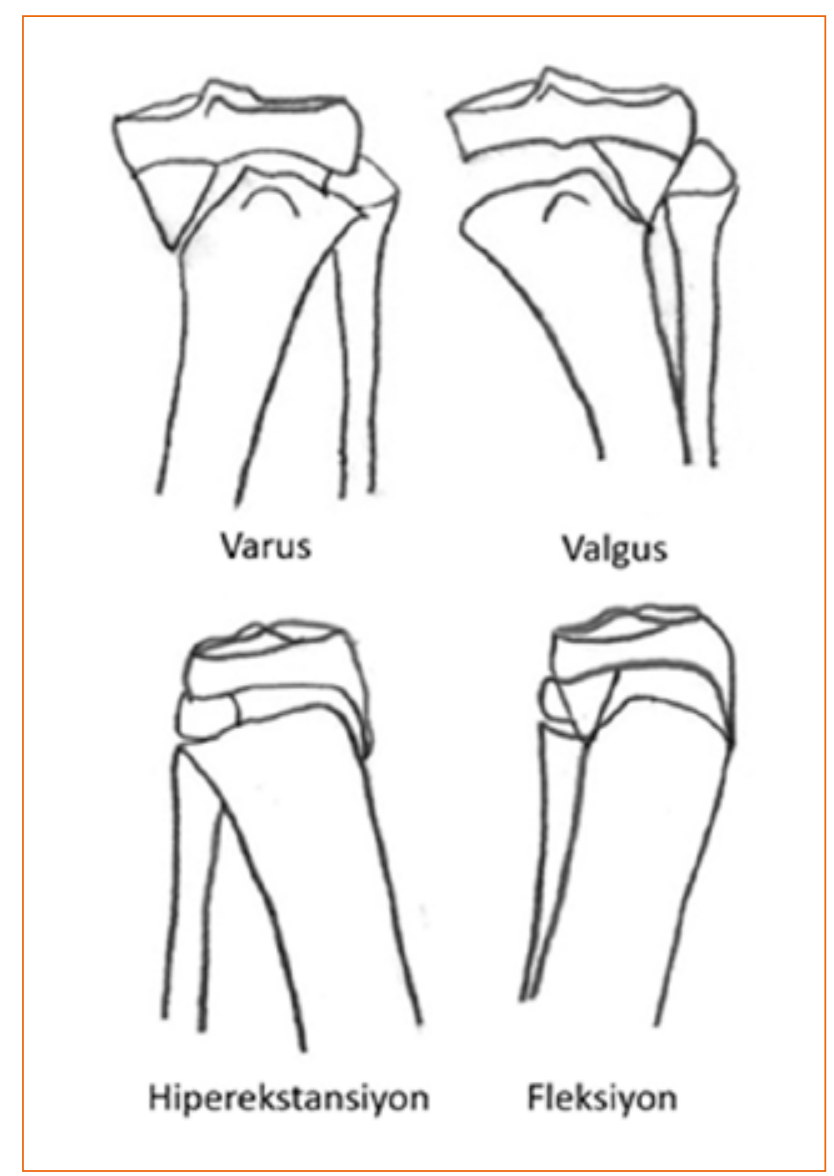

Şekil 10. Tibia üst uç epifizinin yaralanma mekanizmasına göre tanımlanması

edilir. Dengeyi sağlamak için aşıı konumlardan sakınılmalıdır. Konservatif olarak tedavi edilen kırıklar kırı̆̆ın olası bir yer değiştirmesini erken saptamak için ilk iki hafta iki kez radyolojik olarak kontrol edilmelidir. Dört ila altı haftalık bir tespit yeterli olur ve sonra diz rehabilitasyonu programına geçilir.

Cerrahi tedavi yer değiştirmiş ve uygun tespit için aşırı pozisyon verilmesi gereken kırıklara uygulanır.

Kapalı yerleştirme ve perkütan çivileme en sık uygulanan cerrahi yöntemdir. Yerleştirme tekniği kırık tipine bağlıdır. Sedatize edilmiş hastada, uyluk bir asistan tarafindan tespit edilirken uzunlamasına traksiyon uygulanıp, bacak varus tipi kırıklar için valgusa, valgus tipi kırıklar için ise varusa getirilir. Yerleştirmenin uygunluğu skopi ile kontrol edildikten sonra kırık epifizi geçen yivsiz çivilerle tespit edilir. Diz 20-30 fleksiyonda atellenir. Uzuv 24-48 saat süre ile yükseltilir ve soğutulur. Bu süre zarfinda düzenli damar sinir bakısı yapılmalıdır. Şişlik geriledikten sonra diz üstü silindirik alçı 

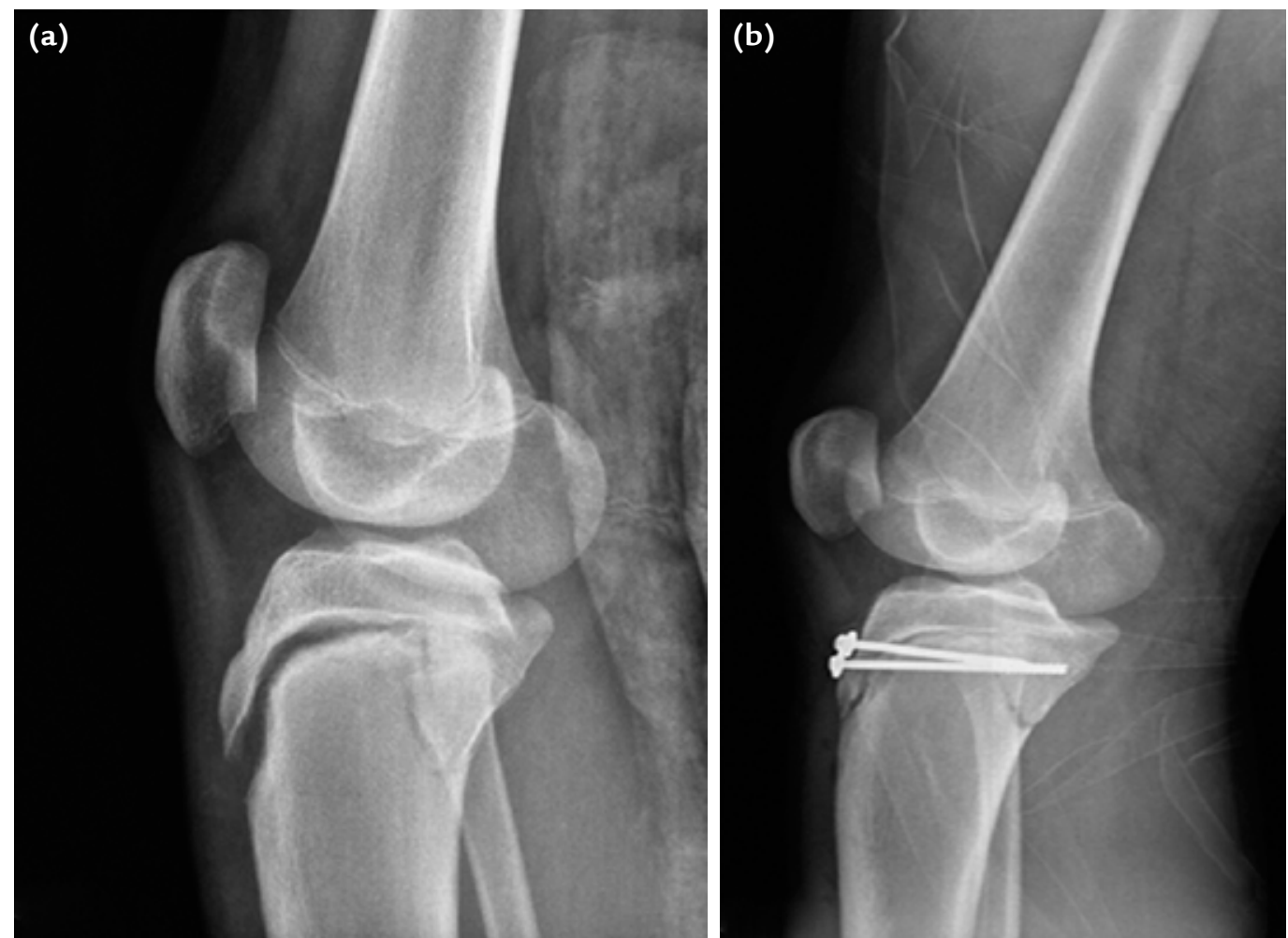

Şekil 11. a, b. Tibia üst uç epifizinin fleksiyon yaralanması (a). Kapalı yerleştirme ve perkütan uygulanmış vida ile tespiti (b).

uygulanabilir. Kırık parçada metafiz parçası varsa bu parçadan perkütan olarak geçirilecek kanallı vidalar tespite yardımcı olabilir (Şekil 11).

Açık yerleştirme, iki kez denemeye rağmen yerleştirilemeyen Tip I ve Tip II kırıklarla eklem bütünlüğünü sağlamak amacı ile yer değiştirmiş Tip III ve Tip IV kırıklara uygulanır. Damar onarımı yapılacaksa, kırığa posterior kesi ile ulaşılıp önce içten tespit yapılır. Kırık, büyüme plağını geçen yivsiz çivilerle tespit edilir. Tip III ve Tip IV kırıklar, büyüme plağını zedelememek amacı ile, epifize yatay olarak yerleştirilen vidalarla tespit edilmelidir. Tip III kırıklara eşlik eden yan bağ yaralanmalarının kırık tespiti sırasında veya kırık iyileştikten sonra gerekirse onarılması konusunda görüş birliği yoktur. ${ }^{[8]}$

Tibia üst uç epifiz yaralanmalarının en ciddi sorunu damar sinir yaralanmalarıdır. Ender görülür, ancak ampütasyon dahil ciddi sorunlara yol açabilir. Damar yaralanmalarının tibia üst uç epifiz yaralanmalarında da akılda tutulup erken tanı ve girişimde bulunulması önemlidir.
Tüm epifiz yaralanmalarında olduğu gibi bu epifiz yaralanmalarında da büyüme bozuklukları görülebilir. Çocuğun yaralanma yaşının küçük olması oranında ciddi kısalık ve şekil bozukluğu görülür. Şekil bozukluğu hatalı kaynama neticesinde oluşmuşsa, osteotomiyi uygulamadan önce yeniden şekillenme göz önünde tutulmalıdır. Sorunlar büyüme plağının tutulmasıyla meydana gelmişse, oluşan şekil bozukluğu ve kısalığı kemik köprünün çıkarılması, osteotomi ve uzatma uygulayarak tedavi etmek mümkün olabilir. Kemik köprü çıkarılmasının etkili olabilmesi için büyüme plağının \%50'den az tutulması ve olgunun en az üç yıl büyüme potansiyelinin olması gerekir.

\section{KAYNAKLAR}

1. Beaty JH, Kumar A. Fractures about the knee in children. J Bone Joint Surg Am 1994;76(12):1870-80. Crossref

2. Mann DC, Rajmaira S. Distrubution of physeal and nonphyseal fractures in 2650 long bone fractures in children aged 0-6 years. J Pediatr Orthop 1990;10(6):713-6. Crossref 
3. Beals RK, Tufts E. Fractured femur in infancy: the role of child abuse. J Pediatr Orthop 1983;3(5):583-6. Crossref

4. Lal H, Bansal P, Khare R, Mittal D. Conjoint bicondylar Hoffa fracture in a child: a rare variant treated by minimally invasive approach. J Orthop Trauma 2011;12(2):111-4. Crossref

5. Wessel LM, Scholz S, Rusch M, Köpke J, Loff S, Duchêne W, Waag KL. Hemarthrosis after trauma to the pediatric knee joint. what is the value of magnetic resonance imaging in the diagnostic algorithm? J Pediatr Orthop 2001;21(3):338-42. Crossref

6. Buess-Watson E, Exner G, Illi O. Fractures about the knee: growth disturbances and problems of stability at long term follow up. Eur J Pediatr Surg 1994;4(4):218-24. Crossref

7. Eid AM, Hafez MA. Traumatic injuries of distal femoral physis. Retrospective study of 151 cases. Injury 2002;33(3):251-5. Crossref

8. Bertin KC, Goble EM. Ligament injuries associated with physeal injuries about the knee. Clin Orthop Relat Res 1983;(177):188-95. Crossref

9. Lombardo SI, Harvey IP. Fractures of the distal femoral epiphysis. J Bone Joint Surg Am 1977;59(6):742-51. Crossref

10. Kasser JR. Physeal bar resections after growth arrest about the knee. Clin Orthop Relat Res 1990;(255):68-74. Crossref

11. Peterson HA. Partial growth plate arrest and its treatment. J Pediatr Orthop 1984;4(2):246-58. Crossref

12. Wiley JJ, Baxter MP. Tibial spine fractures in children. Clin Orthop Relat Res 1990;(255):54-60

13. Zaricznyj B. Avulsion fracture of the tibial eminence treatment by open reduction and pinning. J Bone Joint Surg Am 1977;59(8):1111-4. Crossref

14. Smith JB. Knee instability after fractures of the intercondylar eminence of the tibia. J Pediatr Orthop 1984;4(4):462-64. Crossref

15. Seeley MA, Knesek M, Vanderhave KL. Osteochondral injury after acute patellar dislocation in children and adolescents. J Pediatr Orthop 2013;33(5):511-8. Crossref

16. Mink JH, Deutsch AL. Occult cartilage and bone injuries of the knee: detection, classification, and assessment with MR imaging. Radiology 1989;170(3):823-29. Crossref
17. Hammerle CP, Jacop RP. Chondral and osteochondral fractures after luxation of patella and their treatment. Arch Orthop Trauma Surg 1980;97(3):207-11. Crossref

18. Harper MC, Ralston M. Isobutyl 2-cyanoacrylate as an adhesive in the repair of osteochondral fractures. J Biomed Mater Res 1983;17(1):167-77. Crossref

19. Johnson EW, McLeod TL. Osteochondral fragments of the distal end of the femur fixed with bone pegs. Report of 2 cases. J Bone Joint Surg Am 1977;59(5):677-78. Crossref

20. Matsusue $Y$, Nakamura T, Suzuki S, Iwasaki R. Biodegradable pin fixation of osteochondral fragments of the knee. Clin Orthop Relat Res 1996;322:166-73. Crossref

21. Hensal F, Nelson $T$, Pavlov H, Torg JS. Bilateral patellar fractures from indirect trauma. A case report. Clin Orthop Relat Res 1983;(178):207-9. Crossref

22. Maripuri SN, Mehta H, Mohanty K. Sleeve fracture of the superior pole oh the patella with an intra-articular dislocation. A case report. J Bone Joint Surg Am 2008(2):90;385-9. Crossref

23. Ogden JA, Tross RB, Murphy MJ. Fractures of the tibial tuberosity in the adelocents. J Bone Joint Surg Am 1980;62(2):205-15. Crossref

24. Pandya NK, Edmonds EW, Roocroft JH, Mubarak SJ. Tibial tubercle fractures: complications, classification, and the need for intraarticular assessment. J Pediatr Orthop 2011;32(8):749-59. Crossref

25. Shelton WR, Canale ST. Fractures of the tibia through the proximal tibial epiphyseal cartilage. J Bone Joint Surg Am 1979;61(2):167-73. Crossref

26. Pritchett JW. Longitudinal growth and growth plate activity in the lower extremity. Clin Orthop Relat Res 1992;(275):2749. Crossref

27. Wozasek GB, Moser KD, Haller H, Capuosek M. Trauma involving the proximal tibial epiphysis. Arch Orthop Trauma Surg 1991;110(6):301-6. Crossref

28. Conroy J, Cohen A, Smith RM, Mathews S. Triplane fracture of the proximal tibia. Injury 2000;31(7):546-8. Crossref

29. Sferopoulos NK, Rafailidis D, Traios S, Christoforides J. Avulsion fractures of the lateral condyle in children. Injury 2006;37(1):57-60. Crossref 